\title{
Spectrum Occupancy Measurements and Analysis in the 2.4-2.7 GHz Band in Urban and Rural Environments
}

\author{
Adeseko A. Ayeni, Nasir Faruk, Olayiwola W. Bello, Olugbenga A. Sowande, Samuel O. Onidare, and \\ Mujahid. Y. Muhammad
}

\begin{abstract}
Continuing proliferation of wireless devices exposes humanity to the reality of the twin challenge posed by finite frequency spectrum and almost infinite demand for the same frequency spectrum, necessitating the need for more ingenious spectrum management techniques. The band 2.4-2.7 GHz was originally created and classified for ISM, 3G, UMTS and WiMAX systems. It has become a frequency band which is generally used by end users due to the fact that it's inexpensive, easy to deploy and enhances frequency re-use. Quite a few measurements have been carried out in countries like France, Germany, India, Romania, UK and USA. This paper presents a study of an outdoor measurement on spectrum occupancy in both rural and urban areas in Kwara State, Nigeria, spanning across the frequency range of $2.4 \mathrm{GHz}-2.7 \mathrm{GHz}$. The results show that the band being investigated is immensely underutilized with upper and lower occupancy values of $22.56 \%$ and $0 \%$ in urban and rural environments. These results were compared to other measurements conducted globally in this band or closely aligned bands.
\end{abstract}

Index Terms-ISM band, spectrum occupancy, spectrum utilization, UMTS network.

\section{INTRODUCTION}

Continuing proliferation of wireless devices is bringing to the fore the twin challenge of finite frequency spectrum and almost infinite demand for the same frequency spectrum, dictating the need for the use of more ingenious spectrum management techniques, to accommodate more desirous users. More appealing to scholars and practitioners, worldwide, is the idea of frequency reuse and cognitive radio. This brings about the questions spectrum occupancy versus frequency availability. In recent years the demands of wireless data services have been increasing exponentially, due to global increase in connected mobile devices, such as smart phones. The global monthly data traffic grew by about $69 \%$ from 1.5 exabyte in 2013 to 2.5 exabyte at the end of year 2014 and this is expected to reach up to 24.5 Exabyte in 2019 as forecasted by Cisco visual networking index [1]. In order to meet up with these demands, there is the need to improve on efficient use of the scarcely-available radio spectrum. Accurate assessments of the radio spectrum utilization and profiling are crucial for the development of

Manuscript received November 23, 2015; revised April 20, 2016.

A. A. Ayeni, N. Faruk, O. A. Sowande, S. O. Onidare, and M.Y. Mujahd are with the Department of Telecommunication Science, University of Ilorin, Nigeria (e-mail: aayeni@unilorin.edu.ng, faruk.n@unilorin.edu.ng, sowande.oa@unilorin.edu.ng, onidare.so@unilorin.edu.ng, mujahid.my@unilorin.edu.ng).

O.W. Bello is with the Department of Information and Communication Science, University of Ilorin, Nigeria (e-mail: laibello@unilorin.edu.ng). next generation systems. Not only that, studies have shown that vast amount of the spectrum remain under utilized and also most countries have started implementing some next generation systems such as TV White space technologies [2] which aim to reuse vacant TV spectrum. This will however, require accurate census of available spectrum. The frequency band 2.4-2.7 GHz have been, primarily, allocated to the third generation (3G) wireless systems, Universal Mobile telecommunication Systems, Worldwide Interoperability for Microwave Access (WiMAX) and industrial, scientific and medical (ISM) use. Table I provides details of the licensing and spectrum block for each of the services. There is no global uniformity in licensed-spectrum application, for example the WiMAX Forum [3] has published three licensed spectrum profiles: $2.3 \mathrm{GHz}, 2.5 \mathrm{GHz}$ and $3.5 \mathrm{GHz} .2 .5 \mathrm{GHz}$ is been used in the USA [4], $2.5 \mathrm{GHz}$ and $3.3 \mathrm{GHz}$ in Asia while Pakistan uses $3.5 \mathrm{GHz}$. However, the Radio communication Sector of the International Telecommunication Union (ITU-R), in October 2007, included WiMAX technology in the IMT-2000 set of standards to use the 2.5-2.69 GHz band [5].

The ISM radio bands (i.e. 2.4-2.5 GHz) are the portions of the radio spectrum dedicated by the ITU for industrial, scientific and medical purposes, other than telecommunication. Despite the intent of the original allocations, and because there are multiple allocations, developments in recent years have seen tremendous growth in the use of these bands for short-range, low power communications systems. Other devices that share these bands include Cordless phones, Bluetooth devices, and wireless computer networks.

In recent years, ISM bands have also been shared with (non-ISM) license-free error-tolerant communication applications such as wireless sensor networks, wireless LANs and cordless phones in the $2.45 \mathrm{GHz}$ band. Since unlicensed devices are, characteristically, tolerant of ISM emissions in these bands, unlicensed low power users can be harboured at no risk of interference to co-ISM users.

The Nigerian Communications Commission (NCC) in [6] opened up the ISM to enhance a wider range of services to subscribers, through the provision of last mile broadband access, for final distribution to end users; open up new possibilities for the pleasure and convenience of subscribers. It will also allow home-based users to have access to a variety of IP-based services, thereby enhancing universal service objectives.

This research discusses spectrum occupancy in the 2.4-2.7 $\mathrm{GHz}$ band, with measurements taken in Kwara state, Nigeria, in nine locations that span across rural, suburban and urban 
areas. The work also provides comparison with global occupancy measurement results conducted in this band.

\section{RELATED WORKS}

There has not been active research works conducted in Nigeria, in the area of spectrum occupancy, aside the one presented by Najashi et al. [7]. However, research efforts have been made in [8]-[13] ranging from field survey to protocol and model developments, to improve on spectrum utilization so that secondary use of radio spectrum is possible. Attard et al. [14] provides occupancy rate of the spectrum band of $2.4 \mathrm{GHz}$ using a cooperative sensing technique, with a combination of metrics such as AND, and OR on the measurement data to define the utilization of the spectrum. The low transmission power level results in the utilization of the spectrum being deeply dependent on the location of the measurement. Hoyhtya et al [15] carried out a spectrum occupancy measurement in the 2.3-2.4 GHz band at Turku, Finland and compared this to the situation in Chicago, USA. The Finland measurement was conducted at a single point location located at Turku University of Applied Sciences Sepänkatu campus, on the roof of a four storey building. The Chicago data was collected at Harbor Point, in the eastern part of downtown Chicago. The researchers observed that, there is a need for location specific measurements in the $2.3-2.4 \mathrm{GHz}$ band due to factors such as the limited transmission power of incumbent users in a location. In [16], measurements were carried out on spectrum occupancy in India (Mumbai and Pune) for $700 \mathrm{MHz}-2.7 \mathrm{GHz}$. The main purpose of the survey was to perform a research that would reveal the level of utilization of spectrum of the specified frequency bands in an outdoor area in the suburban of Mumbai, suitable for deploying cognitive radio technology. The results of this research indicated that the average utilization of the spectrum was found to be $6.62 \%$. Adediran et al. [17] provides TV White Space in Nigeria in UHF band: Geo-spatial approach. They provided a map showing the concentration of available radio spectrum within the country. Similarly, in [18] and [19] algorithm for predicting DTV coverage, and protection contour estimation for spatial white space and DTV protection regions for spectrum sharing, respectively, are provided.

Jayavalan et al. [20], carried out measurements and analyses on the utilization of frequency spectrum in the cellular and TV bands in Malaysia. The goal is to quantify the usage of the spectrum and also exploring the possibility of other wireless communication systems or cognitive radio to utilize the unused bands. The result analysis indicated that GSM 900 has an average duty cycle of $35 \%$, GSM $180010 \%$ and $3 \mathrm{G}, 26 \%$. In addition, the VHF of the TV broadcasting bands acquire the average duty cycle of $11 \%$ while the UHF possesses an average duty cycle of $13 \%$. Spectrum utilization on a simultaneous large scale measurement in south china to assess the realistic usage of the spectrum from $20 \mathrm{MHz}$ to 3 $\mathrm{GHz}$ was conducted in [21]. The results reveal that each location has different spectrum usage as follows: for Guangzhou Trade Center \& Guangzhou Canada Garden (urban areas) the average duty cycle are $41 \%$ and $29.8 \%$ respectively while Zhongshan in Suburban, and Jiangmen in rural are $35.9 \%$ and $21.6 \%$ respectively. Chiang et al. [22] studied the usage of spectrum in New Zealand results reveal that the utilization of spectrum, in the band, give the average duty cycle of $6.21 \%$ and $5.72 \%$ in an outdoor and indoor location respectively.

Islam et al. [23], conducted a survey on occupancy measurement in Singapore, The goal was to evaluate the occupancy of the bands of diverse services and discover the possible candidate bands that can be for futuristic usage. The spectrum measurement result shows that the average utilization of the spectrum was established to be just $4.54 \%$ in Singapore.

\begin{tabular}{l|l|l}
\hline \multicolumn{3}{l|}{ TABLE I: SOME LICENSED AND UNLICENSED BANDS WITHIN 2.3-2.7 GHz } \\
\hline \hline Service/system & Frequency & Example \\
\hline 3G wireless & $2.5-2.69 \mathrm{GHz}$ & 3G, UMTS, Wimax \\
\hline $\begin{array}{l}\text { Wireless } \\
\text { communications } \\
\text { service }\end{array}$ & $\begin{array}{l}2.305-2.32 \\
\mathrm{GHz},\end{array}$ & WLAN, Wimax \\
\hline $2.345-2.36 \mathrm{GHz}$ & \\
\hline ISM band II & $2.4-4.835 \mathrm{GHz}$ & Bluetooth,802.11b WLANs \\
\hline U-NIII band I & $5.1-5.25 \mathrm{GHz}$ & $\begin{array}{l}\text { Indoor systems, 802.11a } \\
\text { WLANs }\end{array}$ \\
\hline U-NII band II & $5.2-5.35 \mathrm{GHz}$ & $\begin{array}{l}\text { Short range outdoor } \\
\text { systems,802.11aWLANs }\end{array}$ \\
\hline \hline
\end{tabular}

In [24], bands of frequencies with range from $450 \mathrm{MHz}$ to 5 $\mathrm{GHz}$ were studied, except for $566-606 \mathrm{MHz}$ due to the prohibitions to announce the measurement result by the related civil provisions. The results in china in the band 470-566 MHz and $3400-3700 \mathrm{MHz}$ reveal the frequency occupancy was slightly below 0.4 , which can be $39.5 \%$, also $606-790 \mathrm{MHz}$ above 0.2 which can be $27 \%$, also $1427-1527 \mathrm{MHz}$ above 0.1 , which is $17 \%$ also from $3700-4200 \mathrm{MHz}$ shows above 0.6 which is $66 \%$ occupancy of the spectrum and others are far below 0.1. Ayeni et al. [25] provide spatial Spectrum Utilization Efficiency Metric for Spectrum Sharing System. The work developed an analytical metric that takes into account system parameters to evaluate the efficiency of reusing a spectrum. Spectrum occupancy measurements were cconducted in Barcelona, Spain by Benítez et al. [26] from $75 \mathrm{MHz}$ to $7075 \mathrm{MHz}$. The results revealed that the utilization of the spectrum from $75 \mathrm{MHz}-$ $1000 \mathrm{MHz}, 1000 \mathrm{MHz}-2000 \mathrm{MHz}, 2000 \mathrm{MHz}-3000 \mathrm{MHz}$, $3000 \mathrm{MHz}-4000 \mathrm{MHz}, 4000 \mathrm{MHz}-5000 \mathrm{MHz}, 5000 \mathrm{MHz}$ $-6000 \mathrm{MHz}$ and $6000 \mathrm{MHz}-7075 \mathrm{MHz}$ had an average duty cycle of $42.00 \%, 13.30 \%, 3.73 \%, 4.01 \%, 1.63 \%, 1.98 \%$ and $1.78 \%$ respectively. It was concluded that the study revealed the overall duty circle observed in frequency and time for the stipulated spectrum from $75 \mathrm{MHz}-7075 \mathrm{MHz}$ to give the value of $17.78 \%$ which shows a considerable fact that the entire spectrum experiences low utilization and shows potential for CR usage. In [27] a spectrum survey was conducted which covers two different countries three locations, two locations in France and Czech Republic with the goal of correlating the measurements analysis of the two regions and summarize its similarities and physical aspect that will have to be measured in the future radio spectrum management. The result reveals the overall utilization from $400 \mathrm{MHz}-3 \mathrm{GHz}$ in location 1,2 \& 3 are $6.5 \%, 10.7 \% \& 7.7 \%$ respectively. 


\section{Methodology}

\section{A. Measurement Set up}

The measurement setup and settings used are identical for the rural, urban and sub urban locations. The spectrum occupancy measurement setup consists of a spectrum analyzer, a data storage device, and data manipulation equipment (laptop). Agilent N9342C Handheld Spectrum Analyser (HSA) capable of measuring from $100 \mathrm{KHz}$ to $7 \mathrm{GHz}$ (tuneable to $9 \mathrm{kHz}$ ) was used. The device uses energy detection to directly measures received signal level in $\mathrm{dBm}$. It also capable of displaying the spectrograph of signals. It also has GPS (global positioning system) location features. A 32 Gigabyte Storage device was used to save the log files generated by spectrum analyzer in real-time to be worked on with a laptop. The measurement setup at the locations is shown in Fig. 1.

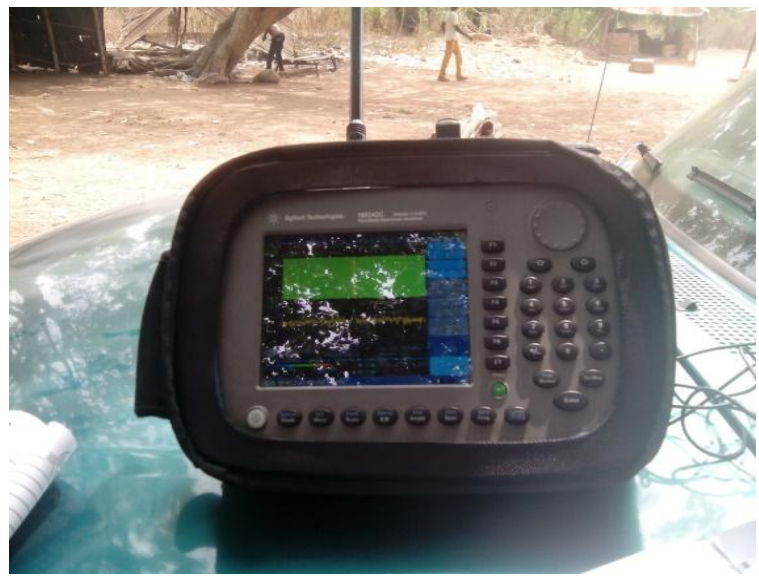

Fig. 1. Agilent N9342C Spectrum analyser and project vehicle.

The SA's parameters were configured according to the values shown in Table II. Analysis of the data was then post-processed offline in a powerful PC.

TABLE II: SPECTRUM ANALYZER CONFIGURATION

\begin{tabular}{l|l}
\hline \multicolumn{1}{c|}{ Parameter } & \multicolumn{1}{|c}{ Value } \\
\hline Resolution/ Video & $100 \mathrm{kHz} / 100 \mathrm{kHz}$ \\
Bandwidth (RBW/VBW) & (Automatically selected by SA) \\
Sweep time & $34.10 \mathrm{~ms}$ (Automatically \\
& selected by SA) \\
Sweep Type & Continuous \\
Reference Level & $-50 \mathrm{dBm}$ \\
Number of points & 461 \\
\hline \hline
\end{tabular}

\section{B. Measurement Locations}

The measurement was conducted outdoors at specific urban and rural locations in Kwara state, Nigeria to ascribe a wide view to our spectrum occupancy. Table III shows the measurement sites and type of environment considered, with their respective coordinates.

\section{Data Collection and Processing}

The measurements were taken for 24 hours in the locations. All raw data was collected by the analyzer in a matrix form with elements of the received signal powers $P\left(f_{i}, t_{i}\right)$ (in $\mathrm{dBm})$. Where $f_{i}$ denotes the frequency or channel and $t_{j}$ records the time slot with 461 as the number of time slots $(\mathrm{N})$ measured per received frame. A total of 1500 frames were received into the Analyzer per band per location. Fifty frames 50 samples were randomly chosen from the raw data leaving a matrix $Y$ of signal power $(50,461)$ to be processed in order to evaluate the occupancy statistics and to produce frequency-time occupancy plots.

\begin{tabular}{|c|c|c|c|}
\hline Location & Type & Coordinate & Identifier \\
\hline $\begin{array}{l}\text { Adio village, Oke } \\
\text { Oyi }\end{array}$ & Rural & $4^{\circ} 29^{\prime} 42^{\prime \prime} \mathrm{E} ;{ }^{\circ} 46^{\prime} 40^{\prime \prime} \mathrm{N}$ & LOC 1 \\
\hline Malete & Rural & $4^{\circ} 29^{\prime} 42^{\prime \prime E ~} 8^{\circ} 22^{\prime} 34^{\prime \prime} \mathrm{N}$ & LOC 2 \\
\hline Alamote & Rural & $4^{\circ} 29^{\prime} 42^{\prime \prime} \mathrm{E} 8^{\circ} 22^{\prime} 34^{\prime \prime} \mathrm{N}$ & LOC 3 \\
\hline Odo Oke & Rural & $4^{\circ} 31^{\prime} 55^{\prime \prime E ~} 8^{\circ} 17^{\prime} 09^{\prime \prime} \mathrm{N}$ & LOC 4 \\
\hline Lagiki, & Rural & $4^{\circ} 33^{\prime} 02^{\prime \prime E ~} 8^{\circ} 16^{\prime} 46^{\prime \prime} \mathrm{N}$ & LOC 5 \\
\hline $\begin{array}{l}\text { University } \\
\text { Quarters, Ilorin } \\
\end{array}$ & Urban & $4^{\circ} 38^{\prime} 47^{\prime \prime E ~} 8^{\circ} 27^{\prime} 49^{\prime \prime} \mathrm{N}$ & LOC 6 \\
\hline $\begin{array}{l}\text { University of } \\
\text { Ilorin, Ilorin } \\
\end{array}$ & Urban & $4^{\circ} 67^{\prime} 60^{\prime \prime}$ E $8.48^{\prime} 74^{\prime \prime} \mathrm{N}$ & LOC 7 \\
\hline Pipe Line & Urban & $4^{\circ} 35^{\prime} 07^{\prime \prime}$ E $8^{\circ} 27^{\prime} 57^{\prime \prime} \mathrm{N}$ & LOC 8 \\
\hline $\begin{array}{l}\text { Kwara Stadium, } \\
\text { Ilorin }\end{array}$ & Urban & 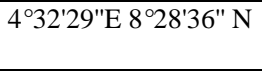 & LOC 9 \\
\hline
\end{tabular}

The process of evaluating the occupancy statistics comprises of three steps- raw data input, setting of an adaptive threshold, and computing the average duty cycle of each channel. Raw data inputs are received power levels at the antenna output that have not been processed. Adaptive threshold setting is done as each channel has different noise power. In order to minimize false alarm, a threshold of $10 \mathrm{~dB}$ above the noise floor was used for this experiment. The average measured occupancy or Duty cycle indicates how often the signal is perceived during a sampled period of scanning a band. The duty cycle is delimited as the percentage of time a frequency band or channel is occupied over a given period as shown in the equation (1)

$$
\text { Duty } \text { Cycle }=\frac{\text { Signal Occupation period }(\mathrm{n})}{\text { Total Observation period }(\mathrm{m})} \times 100 \%
$$

When given a time series of channel power measurements the duty cycle can be calculated as:

$$
\text { Duty Cycle }=\frac{n t}{m} \times 100 \%
$$

where $n$ denotes number of time slots $\mathrm{t}$, where the received signal level is above the decision threshold $\lambda_{j}$ and $m$ is the total number of time slots.

\section{RESULTS AND DISCUSSION}

Table IV shows the results of the occupancy measurement in between 2.4-2.7 GHz band in nine (9) different locations in Kwara state, Nigeria. The locations cut across rural, suburban and urban areas. In Table IV, a duty cycle of $0 \%$ was obtained in locations 1-5 which are all rural areas. This result signifies that the band is completely unoccupied. This is an indication of the low penetration of devices that operate in this band in a typical rural Nigeria settlement that has little or no wireless network infrastructures. However, in the two urban locations 
(LOC $6 \quad \& \quad 7$ ) the results show high occupancy level. Surprisingly the duty cycle of the locations i.e. LOC 6 and LOC 7 are quite higher than for LOC 8 and LOC 9. The occupancy values of $18.56 \%$ and $22.56 \%$ respectively were measured in these locations, which are about a ratio of 20:1 and $17: 1$ when compared to the occupancy of $1.08 \%$ and $0.95 \%$ obtained in LOC 8 and LOC 9. The result is not far-fetched because the locations described as LOC 6 and LOC 7 are campus areas where a lot of wireless LAN devices connect to the institution's internet connection, while LOC 8 and LOC 9 are residential and commercial areas of Ilorin. From an economical point of view the obtained results are very encouraging for cognitive radio technology deployment since lower duty cycle is a desired phenomenon for secondary/opportunistic use of the $300 \mathrm{MHz}$ of available bandwidth within the band. The overall average duty cycle of both the rural $(0 \%)$ and urban settlements $(10.8 \%)$ indicates very low utilization and hence large opportunity for reuse of this band in Kwara state, Nigeria. According to [28], the low occupancy measurements obtained here might be attributed to the fact that this frequency band is usually occupied in indoor environments, hence there is a higher probability that the utilization in indoor might be higher.

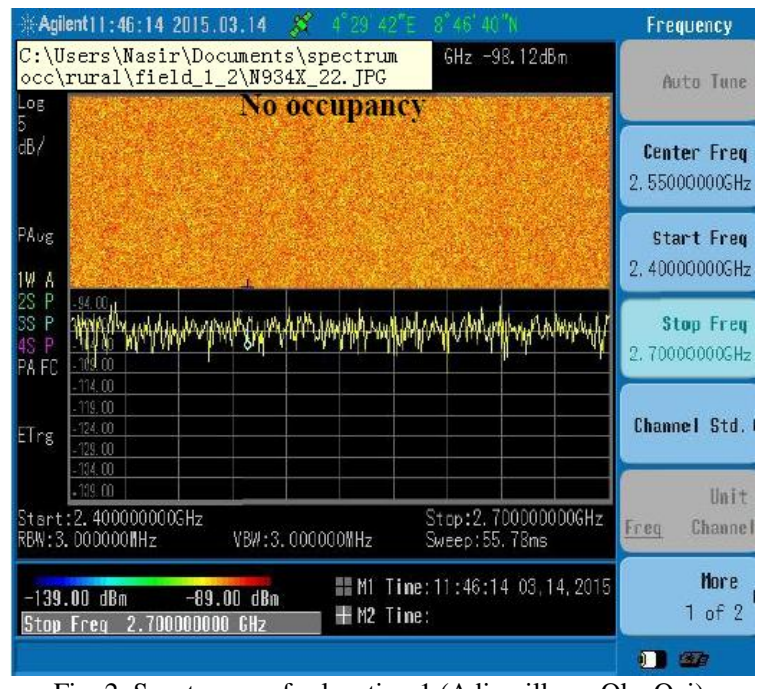

Fig. 2. Spectrogram for location 1 (Adio village, Oke Oyi).

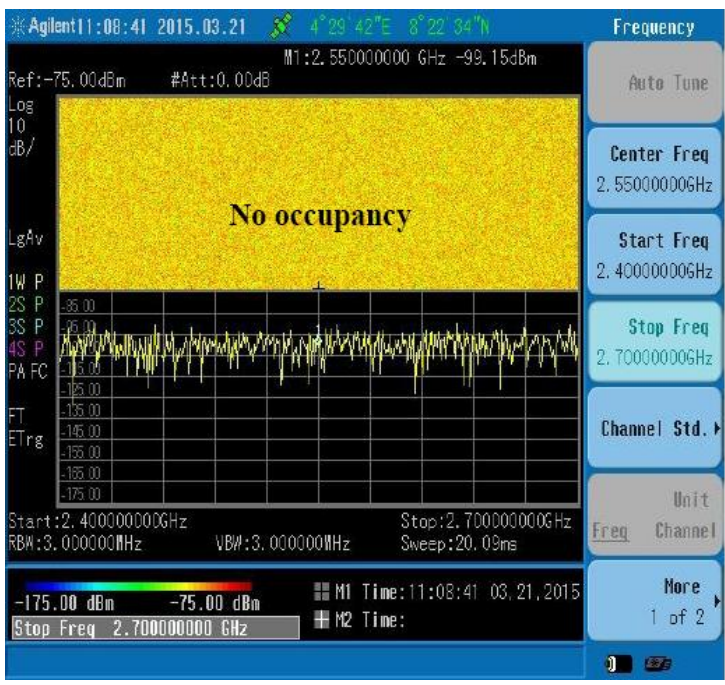

Fig. 3. Spectrogram for location 2 (Malete).

Table $\mathrm{V}$ provides a comparison between measured duty cycle for Kwara State, Nigeria and for some other locations.
Comparing our experiment with [16], it can be shown that in Table V, the occupancy level for Ilorin is higher than Mubai. However these results are location dependents. Results within this band from Mumbai [16], Hull City, UK in [29] and Romania [30] are bit lower than the values obtained. This is expected as the duty cycle in these bands are location dependent. However the results presented in [27] and [9] may not be taken into consideration as the frequency spans of 200 $\mathrm{MHz}$ and $100 \mathrm{MHz}$ which are below $300 \mathrm{MHz}$ used in this experiment.

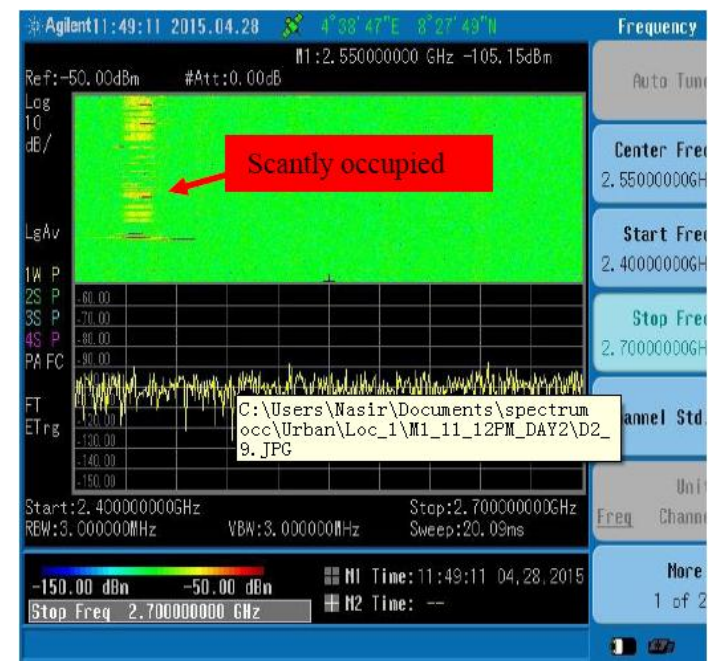

Fig. 4. Spectrogram for location 6 (University of Ilorin Quarters).

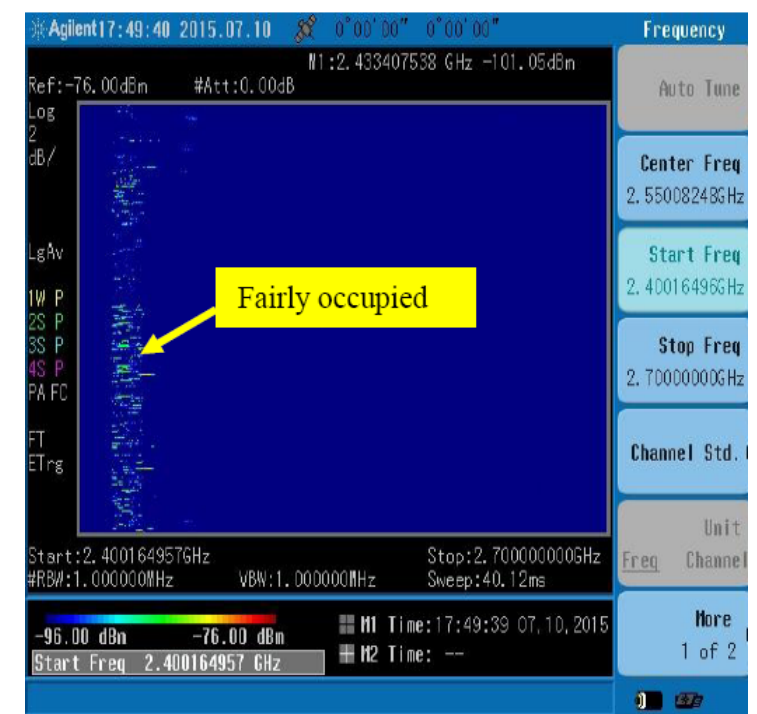

Fig. 5. Spectrogram for location 7 (University of Ilorin, main campus).

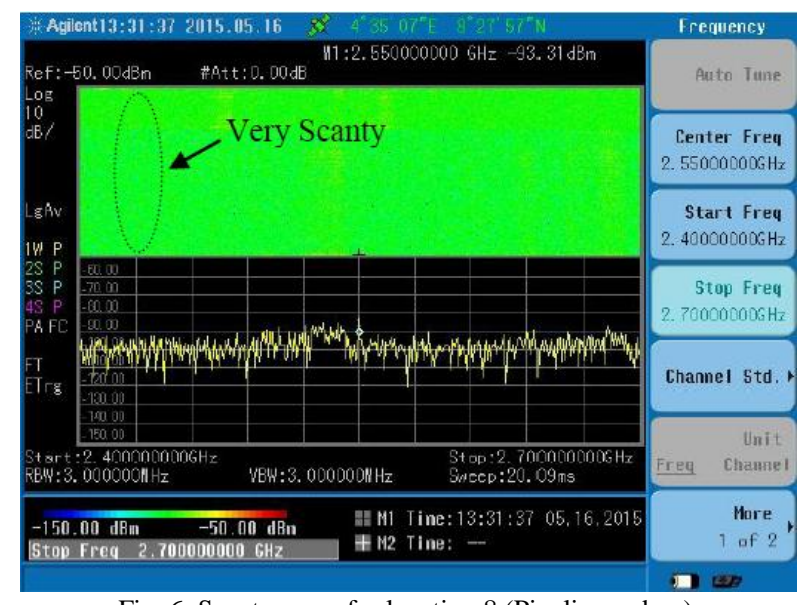

Fig. 6. Spectrogram for location 8 (Pipeline, urban). 
TABLE IV: DUTY CYCLE RESULTS

\begin{tabular}{|c|c|c|c|c|}
\hline $\begin{array}{r}\text { LOCATION } \\
\text { IDENTIFIER } \\
\end{array}$ & LOCATION TYPE & $\begin{array}{c}\text { DUTY } \\
\text { CYCLE }(\%) \\
\end{array}$ & $\begin{array}{l}\text { AVERAGE DUTY CYCLE PER } \\
\text { LOCATION TYPE }\end{array}$ & $\begin{array}{l}\text { AVERAGE DUTY } \\
\text { CYCLE } \\
\end{array}$ \\
\hline LOC 1 & RURAL & 0 & \multirow{5}{*}{$0.00 \%$} & \multirow{9}{*}{$4.79 \%$} \\
\hline LOC 2 & RURAL & 0 & & \\
\hline LOC 3 & RURAL & 0 & & \\
\hline LOC 4 & RURAL & 0 & & \\
\hline LOC 5 & RURAL & 0 & & \\
\hline LOC 6 & URBAN & 18.56 & \multirow{4}{*}{$10.79 \%$} & \\
\hline LOC 7 & URBAN & 22.56 & & \\
\hline LOC 8 & URBAN & 1.08 & & \\
\hline LOC 9 & URBAN & 0.95 & & \\
\hline
\end{tabular}

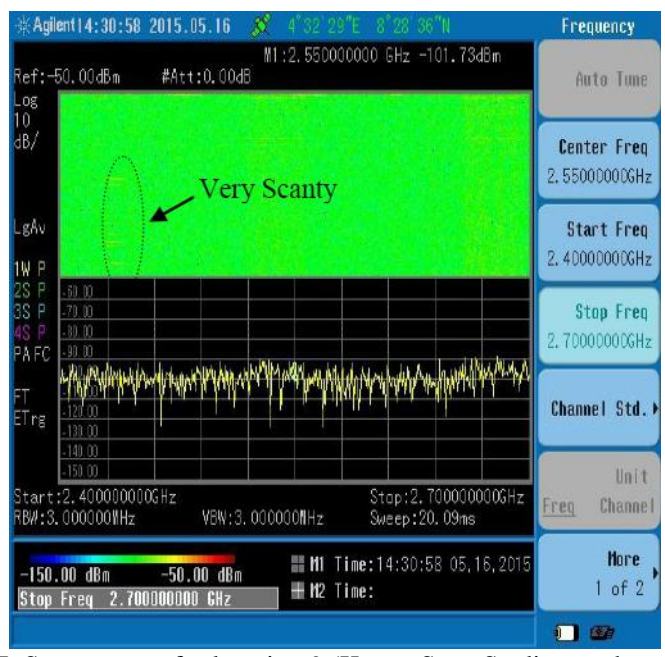

Fig. 7. Spectrogram for location 9 (Kwara State Stadium, urban area).

Fig. 2 to Fig. 7 show the spectrogram for the bands 2.4-2.7 $\mathrm{GHz}$ for six locations. Fig. 2 and Fig. 3 show the spectrogram for rural locations 1 and 2. The figures show no activities going on because there is no active wireless access point within the locations. Fig. 4-7 show the spectrogram for the urban locations. It is worthy of note that within these locations, only locations 6 and 7 show significant activities in the spectrogram. Due to the low occupancies in locations 8 and 9, the activities on this band were not captured on the spectrogram.

TABLE V: COMPARISON BETWEEN MEASURED DUTY CYCLE AND FOR OTHER LOCATIONS

\begin{tabular}{|c|c|c|}
\hline Location & $\begin{array}{l}\text { Average duty } \\
\text { cycle } \%\end{array}$ & $\begin{array}{l}\text { Frequency Band } \\
(\mathrm{GHz})\end{array}$ \\
\hline Ilorin, Nigeria & 10.79 & $2.4-2.7$ \\
\hline Romania $^{[30]}$ & 5.81 & $2.4-2.7$ \\
\hline Hull, $\mathrm{UK}^{[29]}$ & 9.40 & $1.9-2.7$ \\
\hline Abuja, Nigeria $^{[9]}$ & 17.42 & $2.2-2.4$ \\
\hline Mumbai, India ${ }^{[16]}$ & 0.41 & $2.4-2.7$ \\
\hline Czech $^{[27]}$ & 0.20 & $2.4-2.5$ \\
\hline Paris, France ${ }^{[27]}$ & 6.10 & $2.4-2.5$ \\
\hline
\end{tabular}

\section{CONCLUSIONS}

In this paper, we presented an outdoor measurement on spectrum occupancy in both rural and urban areas in Kwara State, Nigeria, spanning across the frequency range of 2.4 $\mathrm{GHz}-2.7 \mathrm{GHz}$. The results obtained show that the band is immensely underutilized. There is, therefore, ample opportunity for the deployment of cognitive radio devices in the investigated band on account of low usage manifested by low occupancy.

\section{ACKNOWLEDGMENT}

This research was conducted under the auspices of the Communication and Networking Research Group (CNRG) of Department of Telecommunication Science, University of Ilorin, Ilorin, Nigeria. The authors would like to express their sincere appreciations to University of Ilorin for purchasing the dedicated Agilent spectrum analyzer used for this study.

\section{REFERENCES}

[1] Cisco Visual Networking Index: Global Mobile Data Traffic Forecast Update. (2014-2019). [Online]. Available: http://www.cisco.com/c/en/us/solutions/collateral/service-provider/vis ual-networking-index-vni/white_paper_c11-520862.html

[2] I. Opawoye, N. Faruk, O. W. Bello, and M. Olufem, "Recent trends on TV white space deployments in Africa" Nigerian Journal of Technology (NIJOTECH), University of Nnsuka, April 2015.

[3] WiMAX Forum. (2015). [Online]. Available: http://www.wimaxforum.org/resources/technical-specifications

[4] FCC. (2015). U.S. Frequency Allocation Chart. [Online]. Available http://www.ntia.doc.gov/files/ntia/publications/2003-allochrt.pdf

[5] ITU. (2015). [Online]. Available: http://www.itu.int/newsroom/press_releases/2007/30.html

[6] NCC. (2015). [Online]. Available: http://www.ncc.gov.ng/

[7] B. G. Najashi, F. Wenjiang, and C. Kadri, "An insight into spectrum occupancy in Nigeria," IJCSI International Journal of Computer Science Issues, vol. 10, no. 1, pp. 394-399, 2013.

[8] N. Faruk, M. Ali, and M. Gumel, "Interference mitigation MAC protocol for cognitive radio networks," Wireless Engineering and Technology (WET), Scientific Research Publication, Inc., USA, vol. 3, no. 2, 2012.

[9] N. Faruk, A. A. Ayeni, and Y. A. Adediran, "Impact of path loss models on spatial TV white space," European Scientific Journal, University of Azores, Portugal, vol. 4, pp. 543-547, 2013.

[10] O. D. Babalola et al., "Spectrum occupancy measurements in the TV and CDMA bands," in Proc. IEEE International Conference on Cyberspace, Abuja, Nov. 4-7, 2015, pp, 192-196.

[11] N. Faruk, Y. A. Adediran, and A. A. Ayeni, "On the study of empirical path loss models for accurate prediction of TV signal for secondary users," Progress in Electromagnetic Research (PIER) B, USA, vol. 49, pp. 155-176, 2013.

[12] O. D. Babalola et al., "Short-term variation of duty cycle in the VHF and UHF bands," in Proc. IEEE International Conference on Cyberspace, Abuja, 2015, pp. 197-201.

[13] N. Faruk, M. Gumel, A. Oloyode, and A. Ayeni, "Performance analysis of hybrid MAC protocol for cognitive radio networks," Int'l $J$. of Communications, Network and System Sciences, vol. 6, no. 1, 2013, pp. 18-28.

[14] R. Attard, J. Kalliovaara, T. Taher, Jesse T. J. Paavola, R. Ekman, and D. Roberson, "A high-performance tiered storage system for a global spectrum observatory network," presented at $20149^{\text {th }}$ International Conference on Cognitive Radiooriented Wireless Networks (CROWNCOM).

[15] M. Höyhty, M. Matinmikko, X. Chen, J. Hallio, J. Auranen, R. Ekman, J. Röning, J. Engelberg, J. Kalliovaara, T. Taher, A. Riaz, and D. Roberson, "Measurements and analysis of spectrum occupancy in the 2.3-2.4 GHz band in Finland and Chicago," presented at International 
Conference on Cognitive Radio Oriented Wireless Networks and Communications (CROWNCOM), June 2014.

[16] K. Patil, K. Skouby et al., "Spectrum occupancy statistics in the context of cognitive radio," in Proc. 14th International Symposium on Wireless Personal Multimedia Communications, pp. 486-490, Brest, France, October 3-7, 2011.

[17] Y. A. Adediran, N. Faruk, A. A. Ayeni, O. Kolade, N. T. Surajudeen-Bakinde, and O. W. Bello, "TV white space in Nigeria in UHF band: Geo-spatial approach," in Proc. IEEE 6th International Conference on Adaptive Science \& Technology (ICAST), pp. 1-6, Oct. 2014.

[18] N. Faruk, A. A. Ayeni, and Y. A. Adediran, "DTV coverage and protection contour estimation for spatial white space," in Proc. IEEE International Conference on Emerging \& Sustainable Technologies for Power \& ICT in a Developing Society, pp. 96-99, Imo, Nigeria July $31^{\text {st }}, 2013$.

[19] N. Faruk, N. T. Surajdeen, O. Kolade, A. A. Ayeni, and Y.A. Adediran, "DTV protection regions for spectrum sharing," IET Journal of Engineering, Institute of Engineering and Technology, 2014

[20] S. Jayavalan, H. Mohamad et al., "Measurements and analysis of spectrum occupancy in the cellular and TV bands," 2014.

[21] Y. Liang et al., "Quantitative spectrum occupancy evaluation in China: Based on a large scale concurrent spectrum measurement," pp. 122-128, 2012.

[22] R. I. C. Chiang, G. B. Rowe, and K. W. Sowerby, "A quantitative analysis of spectral occupancy measurements for cognitive radio," in Proc. IEEE Vehicular Technology Conference (VTC), Dublin, Ireland, April 2007.

[23] M. Islam, G. L. Tan et al., "Spectrum survey in Singapore: Occupancy measurements and analyses," in Proc. of International Conference on Cognitive Radio Oriented Wireless Networks and Communications (CROWNCOM), Singapore, May 2008, pp. 1-7.

[24] SRMC \& GSMA, "Radio spectrum resource assessment of the band $450 \mathrm{MHz}$ to $5 \mathrm{GHz}, " 2014$

[25] A. A. Ayeni, N. Faruk, N. T. Surajudeen-Bakinde, R. A. Okanlawon, and Y. A. Adediran, "Spatial spectrum utilization efficiency metric for spectrum sharing system," Intr J of Digital Information and Wireless Communication, vol. 5, no. 1. Pp. 44-51, 2015.

[26] M. L. Benítez, F. Casadevall, A. Umbert, J. Pérez-Romero et al., "Spectral occupation measurements and blind standard recognition sensor for cognitive radio networks," presented at the 4th International Conference on Crowncom, 2009.

[27] V. Valenta, R. Marsalek, G. Baudoin, M. Villegas et al., "Survey on spectrum utilization in Europe measurements, analyses and observations," Digital Object Identifier: 10.4108/ICST.CROWNCOM 2010.

[28] V. N. Bao, "Vietnam spectrum occupancy measurements and analysis for cognitive radio applications," Advanced Technologies for Communications (ATC), Aug. 2011.

[29] M. Mehdawi et al., "Spectrum occupancy survey in HULL-UK for cognitive radio applications: Measurement \& analysis," International Journal of Scientific \& Technology Research, vol. 2, no. 4, pp. 231-236, 2013.

[30] A. Martian et al., "Evaluation of spectrum occupancy in an urban environment in a cognitive radio context," International Journal on Advances in Telecommunications, vol. 3, no. 3, pp. 172-181, 2010.

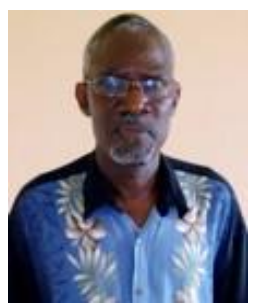

Adeseko Ayeni holds a Ph.D in electrical engineering, specializing in telecommunications. His industrial experience spanned Nigerian Telecommunication Limited and Siemens where he worked as a telecommunication engineer for about six years. He attended short courses in telecommunications in the Bell Telephone Manufacturing Center, Antwwerp, Belgium and Siemens Training Center, Munich, W. Germany. He joined academics in 1992 and has being teaching and conducting researches in Telecommunication and allied subjects. He was visiting research scholar with the Wireless Network Communication Laboratory of the Tennessee Technological University, USA during which he worked with the cognitive radio research group for three months, Oct. to Dec. 2010.

Dr. Ayeni is currently the Ag. head of Department Telecommunication Science, University of Ilorin. He has published journal papers in telecommunication. His current research interest includes radio propagation and cognitive radio communication. He is a COREN registered engineer with membership of the NSE and IEEE.

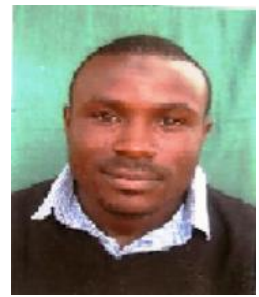

Nasir Faruk is a lecturer in the Department of Telecommunication Science, University of Ilorin, Ilorin, Nigeria. He received his B.sc (Hons) in physics with first class honours from KUST Wudil, Kano State, Nigeria and the M.sc in mobile and high speed telecommunication networks with distinction from Oxford Brookes University, Oxford, UK.

$\mathrm{He}$ has completed his $\mathrm{PhD}$ research in electrical and electronics engineering at University of Ilorin, Ilorin, Nigeria, where we worked on the development of models for efficient exploitation of TV white space in Nigeria. He has published in journals and conference proceedings. His current research interest includes design, analysis and optimization of wireless communication networks, spectrum management, channel modeling, disaster and public safety networks. He is member of IEEE and IET.

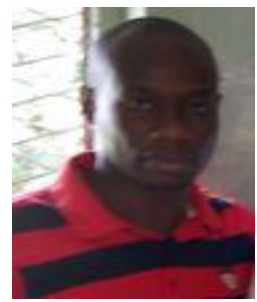

Olayiwola Wasiu Bello holds a master degree in information science and a master of business administration (MBA) with bias for IT operations management. $\mathrm{He}$ presently lectures in the Department of Information and Communication Science, University of Ilorin, Ilorin Nigeria. His research interests span the area of improving businesses with information technology and decision science. He is also a member ITIL

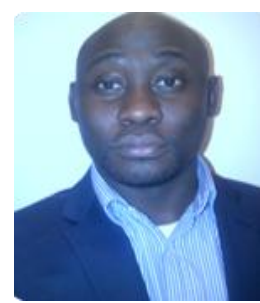

Sowande Olugbenga A. concurrently received both HND in electrical electronics engineering (telecommunication options) and B.Sc (Hons) in physics electronics from Rufus Giwa Polytechnics Owo and Adekunle Ajasin University, Akungba Nigeria in 2007 and 2006 respectively. He received an M.Sc degree in data telecommunication and networks from University of Salford, Greater Manchester, United Kingdom in 2010. He has received both training and passed certification courses in CISCO and MICROSOFT to mention a few and has four years experience working has a server/network engineer in United Kingdom. His currently a lecturer at the Department of Telecommunication Science, University of Ilorin, Nigeria, teaching wireless communication, networking and server management. His current research interest includes cognitive radio communication and next generation networks in wireless communication.

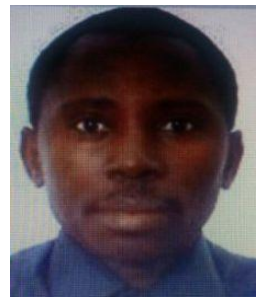

Samuel Olusayo Onidare holds a master of science degree in electrical engineering with emphasis on telecommunications at Blekinge Institute of Technology, Karlskrona Sweden Between July 2000 and June 2001, he worked as a maintenance engineer in Consolidated Breweries Nigeria Plc from where he moved to Ogun-Osun River Basin Development Authority (ORBDA) as electrical engineer II. Between March 2002 and September 2008, he worked for NAL Bank Plc, EIB International Bank Plc, Skye Bank Plc and Oceanic Bank International Plc, all in Lagos, Nigeria. He also had stints with Voiptelesat, and Finnovate limited. He is currently a lecturer in the department of Telecommunication Science University of Ilorin. He is a COREN registered engineer with membership of the IEEE. His research interest includes Wireless communication and network security.

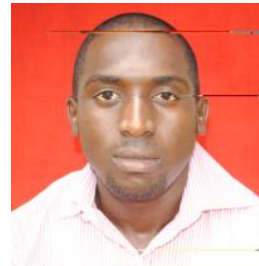

Mujahid Muhammad) holds an MSc in telecommunications engineering and a B.Sc. in computer engineering. He joined academics in 2011 and has being teaching and conducting research activities in telecommunication and networking, at the Department of Telecommunication Science, University of Ilorin, Nigeria. He has published some journal papers in telecommunication and networks. His current research interest includes adhoc network, QoS in VoIP and smart spectrum access. 